\title{
The Residential Subdivision under the Influence of the Unfinished Densification (Case Study for Subdivisions in Setif, Algeria)
}

\author{
By Dhia Eddine Zakaria Lacheheb ${ }^{1}$, Amor Ballout ${ }^{2}$
}

\begin{abstract}
Today, it is necessary to be thrifty for its planet, on one hand the space being a rare, non-renewable resource, and on the other hand the ecological, economic and social cost of the urban sprawl. It is commonly asserted that the promotion of a more compact and dense city has a positive effect in terms of public costs of investment, functioning and costs for the citizens and the users of the city. It is clear that the modes of urban development management have to evolve profoundly, in particular towards a densification favorable to the raising of the urban quality through an ideal urban density on the scale of the individual housing estate. The lot as an individual housing estate was adopted as an alternative development model to the collective housing, thought in an anthropocentric perspective to emerge as a quality model where the density plays an important role, by being included in operations of a global coherence, in an optimal organization without forgetting the main importance of the deadlines of construction and the finalization of the works. The image of eternal construction site inflicted to our cities explains the renewed interest for the application of the regulatory framework and the completion of these limited operations without global coherence, which are summed up in our case to a ground cut in plots of land, sold then built independently without being finished, and support the relevance of the essential question of the improvement of the outside aspect bound to the appearance which can be revealed as a so important factor for a better use and a better acceptance of its housing environment, that the ratio of a number of houses on a plot of land or the number of square meters by house. To demonstrate the impact of the completion degree of the subdivision dwellings, roads system and urban public utilities on the density or the densification and therefore on the urban quality, we studied two residential subdivisions, the private subdivision Sellam and the subdivision El Imane with a common situation, and a different land surface, density and cutting, being occupied by various social classes, with different needs and different household average size. The approach of this work is based on the typo morphological analysis to reveal the differences in the degrees of completions of the subdivision's built environment and on the investigation, by a household's survey, to demonstrate importance of the degree of completion and to reveal the conditions of qualitative densification favorable and convenient to a better subdivision's appropriation.
\end{abstract}

Keywords: Subdivision, Degree of completion, Densification, Urban Quality.

\section{Introduction}

Algeria knew series of several politics, different even opposite, experimented in a record period, in a total extremism from the quite planned after its independence in 1962, to the most liberal after 1990. In a context marked by the fluctuating political, economic and social conditions as well as by the changeable architectural trends, the individual housing and its environment became the most desired by the Algerian inhabitants even if it was not a product of an anticipated urban politics. 
The public authorities' attention was diverted when according a particular importance to the subdivisions and their developments which in spite of being covered by a large outfit of instruments are still facing innumerable tensions.

We were interpellated by the poor maintenance of the old districts and neighborhoods, the speculations on the rents and grounds that leaded to an unfinished densification, besides the problems of the urban management and the unfinished aspect of the new houses where the quantity dominates on the quality, as shows the same deficit and the continuous transformations. From now on, the concerns should be rather focused on the quality of density and the completion of the operations in progress and the upcoming ones, same as the illicit housing environment.

\section{Urban quality}

A heterogeneous notion, made by a series of components in connection with other aspects of the residential experience which make the security of a subdivision, promote its image and define the lot as home and lead us straight ahead to its conceptualization as a system which implies an interaction between the physical environment of the lot and the suitability, the safety and the comfort of its inhabitants. An urban quality where interact social factors, personal and physical factors subjected to the design. (Da Cunha, 2014)

It's now a question of wondering about the level of the urbanity and the subdivision's quality that can be reached in a context of high density (the lots study case)

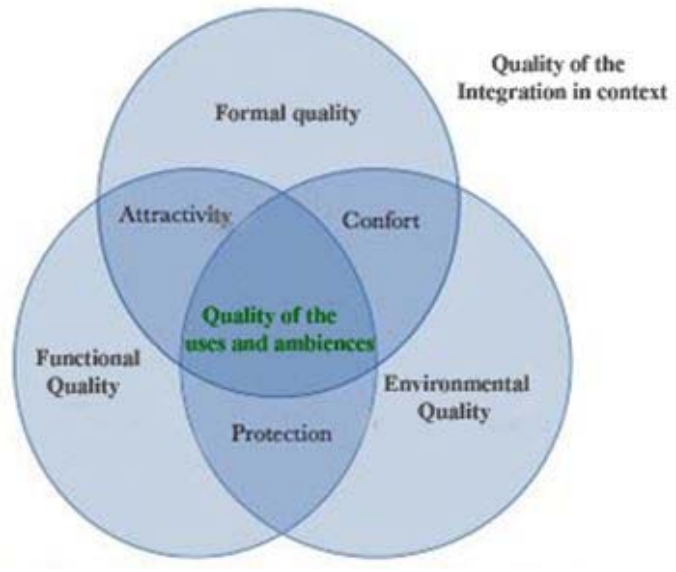

Figure 1: The dimensions of the urban quality

Source: Da Cunba, 2014

\section{Toward a sustainable or a profitable city?}

Today, the evolution of the households and the lifestyles implies a more flexible approach of the individual habitat, to answer variable needs; it involves new ways of conceiving it for proximity without promiscuity. Indeed, for multiple reasons, the production of a more compact and denser frame would be more effective and profitable for the community (FOUCHIER V, 1998). This is why authorities started attempts at damping of the increasingly unverifiable urban sprawl, through a reconquest of the greyfields and waste lands, and the promotion of individual dense habitat in subdivisions and cooperatives by specific operations of densification, urban renewal and other uncontrolled opportunist actions. 


\section{Problematic}

After having initially outlined the portrait of the current and specific situation of the urbanisation process in Algeria where the residential cities of individual habitat, dominate the other shapes of habitat. We might reveal the urban densification of our cities as a requalification and a renewal operation that should be supported by a revalorization of the produced residential architecture.

An urban quality affected by violations, infractions and a non compliance to the regulation into the residential subdivision, where the external aspect of the constructions and their immediate environment inflicts the aspect of an eternal building sites to the dwellings and the subdivision. Consequently, the unfinished aspect is not only involved in the ugliness of the subdivision but in the urban landscape of the built framework of the whole city.

\section{Hypothesis}

The unfinished aspect of the built environment would constitute an obstacle for the perceived urban quality.

\section{Methodology of approach}

Between the evaluation's methods of the design quality of subdivision and those related to the dwelling and houses, which usually proceed by the evaluation of the preferences and the users requirements (Goodchild, 1997; Lawrence, 1984; Leung, 1993; Karn and Sheridan, 1997).

We essentially considered choosing universal methods evaluation, in order to develop the production process of individual habitat in subdivision, to seize and analyze the relevant data of the environment, land market, housing and the essential needs. (Ground, climate, constraints, landscape, ground uses, existing frame).

1) Methods based on the user's direct participation in the design.

2) Those which are based on questionnaires and investigations.

3) The methods that are based on the behaviour's analysis.

"If you want to find out something about has person, surely the best way is to ask him" (Lawrence 1984:180).

The approach of this work is mainly based on the investigation of the households in order to distinguish the formal-aesthetic qualities of the external appearance (Dehan Ph, 1999) and the typo morphological analysis to reveal the differences of the degrees of completion in the built environment and to detect the conditions of a densification of quality, favourable to the subdivision's inhabitant's fulfillment.

\section{Presentation of the case of study}

\subsection{Morphology of the site}

The subdivisions case of study, are both located between 1000 and $1100 \mathrm{~m}$ of altitude in the North west side of the City of Setif, $300 \mathrm{Km}$ to the East of Algiers the capital of Algeria, borded by a 750 collective dwellings from the east, the University UFAS from the south. The subdivision are situated on in important incline (Gradually from East to west towards the South) and near avoidance RN 9 . 


\subsection{Size of the lots}

\subsubsection{Number and distribution of islands:}

In spite of the number of islands in the two subdivisions, more or less equal, the land reserved to the subdivision is by far unequal, the Sellam subdivision (Subdivision 1) realized on an entire surface of $63810 \mathrm{~m}^{2}$, while the subdivision El Imane (Subdivision 2) rests on $23020.25 \mathrm{~m}^{2}$ $(1 / 3$ of the Subdivision 1$)$.

This difference of land surface and many small islands for almost the same number of lots imposed an irregularity in the distribution amongst the lots in small islands (Figure 2: Comparison of the lots number/islands). Recording a maximum of 34 islands (small island E Subdivision 1) and 24 islands (small island J Subdivision 1).

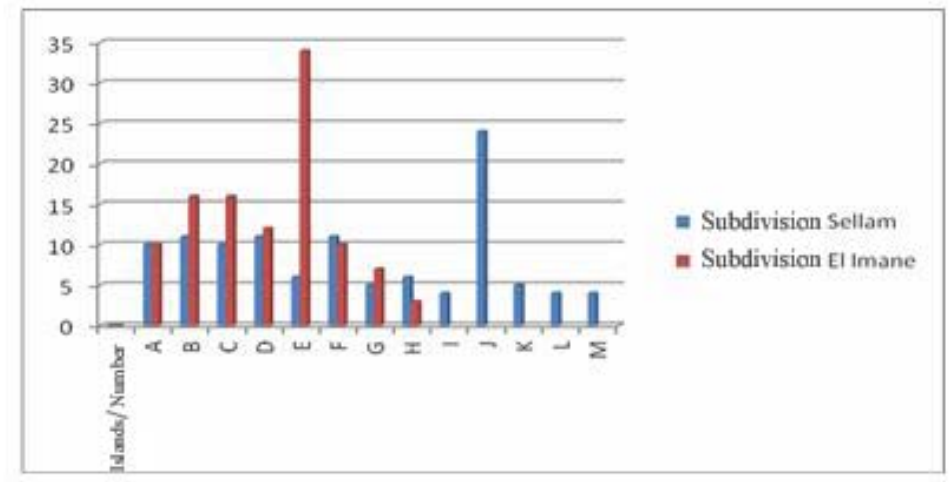

Figure 2: Comparison of the lots number/ islands

Source: Data of the survey established by the author

The differences mentioned above, engendered different densities (lots / island), from simple to double, 22 lots / hectare in the 1st subdivision, and 48 lots / hectare, 2nd subdivision, even differences of distributions of the density within the subdivision.

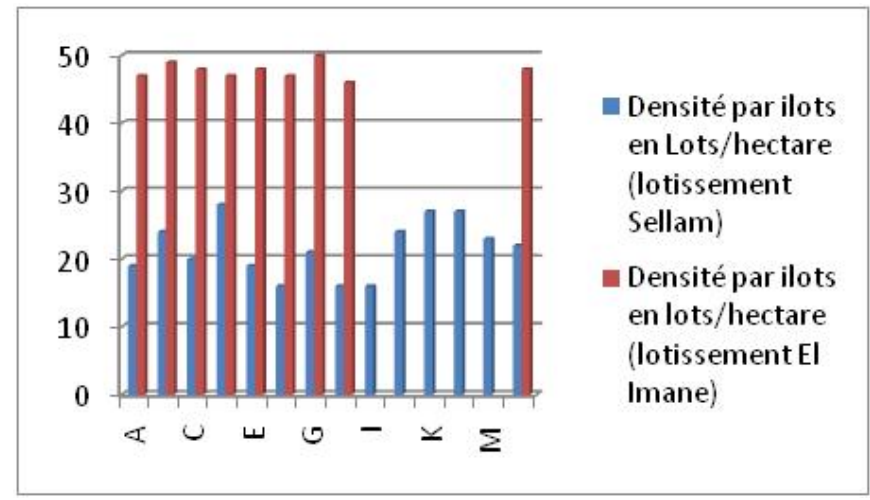

Figure 3: Distribution of the densities in islands lots / islands)

Source: data of the survey established by the author

\subsubsection{Islands Surface:}

The surfaces of islands are unbalanced quite so much, and unevenly distributed, this can be revealant about the cutting and street layout (Figure 4: Comparison of islands' surfaces) 


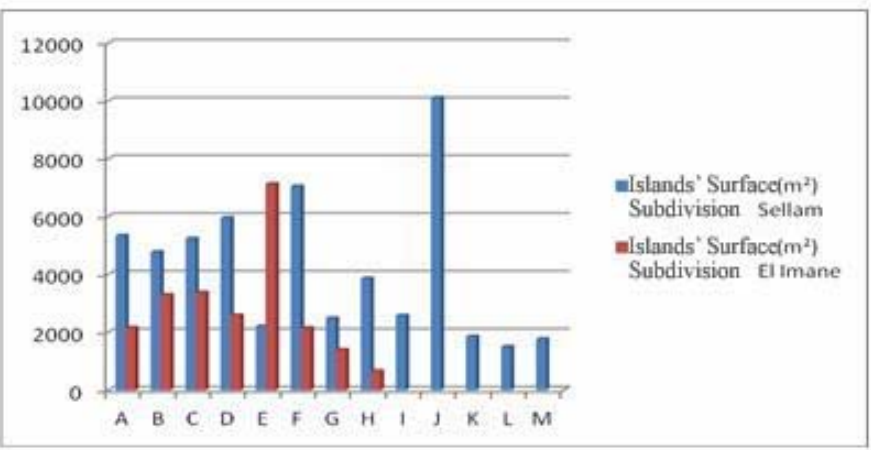

Figure 4: Comparison of islands' surfaces

Source: data of the survey established by the author

\section{Setting-up the built and requirement specifications}

The majority of the lots in the (Subdivision 1) are of a very important surface. According to the requirements of the specifications, the coefficient footprint (C.E.S) should not exceed 50\% of the entire surface of the construction of the lot, and the Order $n^{\circ} 1661$ of the $5 / 5 / 1971$, that is still applicable stipulates that the lots having a surface equal or higher than $300 \mathrm{~m}^{2}$ will have to comprise only $50 \%$ maximum of built surface.

The (Z.N.A) must have a withdrawal of 3 meter of construction compared to the road No construction can have a direct sight with the neighboring property with less 4 meters.

The observance of the regulation and the regulations of the specifications should make the enjoyment of a minimum of comfort and freedom possible to each resident of the subdivision.

\subsection{Heights of the constructions}

On another plan, the regulations of the specifications fix the height of constructions at $11 \mathrm{~m}$, starting from the level of the way of the principal frontage, the equivalent Ground floor +2 . The required objective is safeguard and homogeneity relatives to the general panorama of the site. However, the established report emphasizes a diversity of a situation that varies from the waste ground ground floor+1 until cases of ground floor+4 type, with intermediate situations type ground floor +2 and ground floor +3 .

Houses shaped like buildings of superposed dwellings, dominated by an extension in height especially when it comes to inhabitants that made their ground floor a workplace.

Such diversity creates a mosaic of houses with forms and different jigs that emphasize the great contrast observed in the establishment's zone.

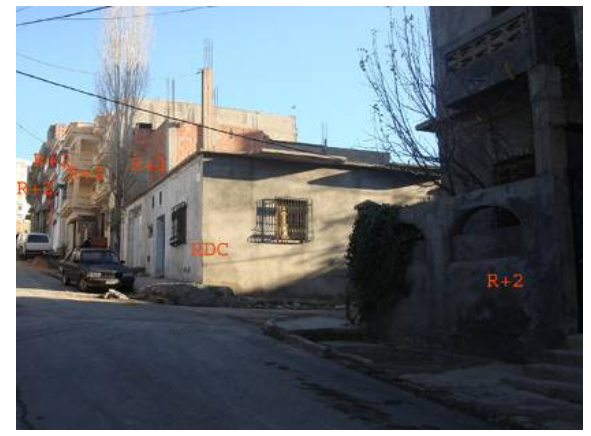

Photo 1: Different heights (Subdivision 02); Source: The author (2014) 


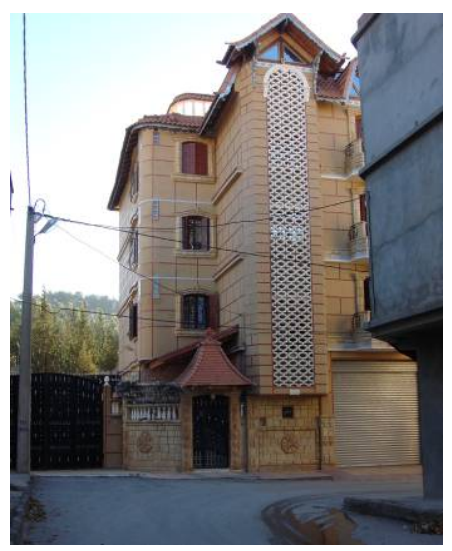

Photo 2: 3 Levels +height (subdivision02); Source: The author (2014)

\subsection{Degree of completion of houses and outer spaces}

According to the investigation that we carried out, the impact of the degree of completion on the appearance of the built and non built frame, on the perceived quality of dwelling in the subdivision is undeniable.

In the 2nd subdivision we recorded contrasts of dwellings (Photo 3: Unfinished dwellings, subdivision 2, Photo 4: Achieved house, subdivision 2), and of the paradoxes in the speeches and answers of the inhabitants, in particular of inhabitants of the unfinished dwellings, which estimate that their dwellings are completed, and thus do not plan to undertake work of completion.

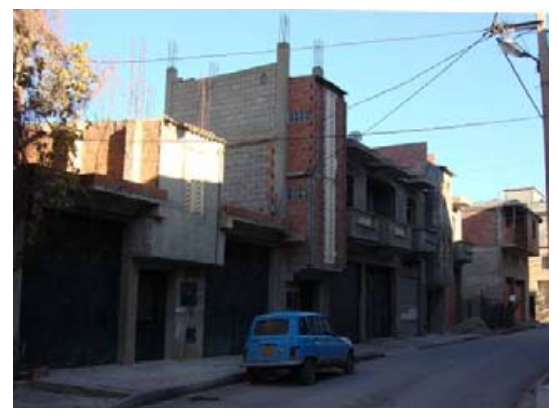

Photo 3: Unachieved houses, Subdivision 2; Source: The author (2014)

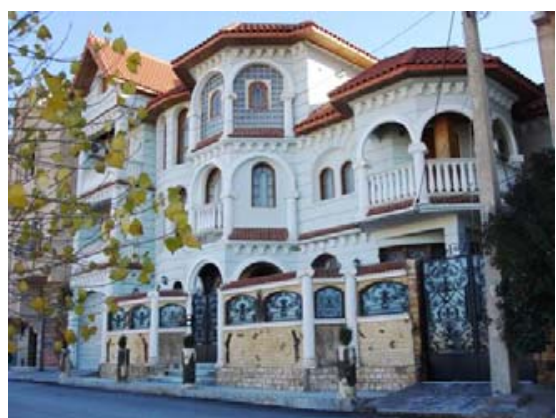

Photo 4: Achieved house, Subdivision 2; Source: The author (2014) 
We note that the inhabitants of the 1st subdivision with a dominant typology, and low density carry out and plan to carry out works of completion of their even completed dwellings! (Perpetual search of quality by embellishment). The personalization with materials and colors explains the inhabitants' appropriation and appreciation, expressing their wish to entertain and remain (94\% wish to remain there). The degree of completion proves to be determining in the perception of quality and the access to residential satisfaction.

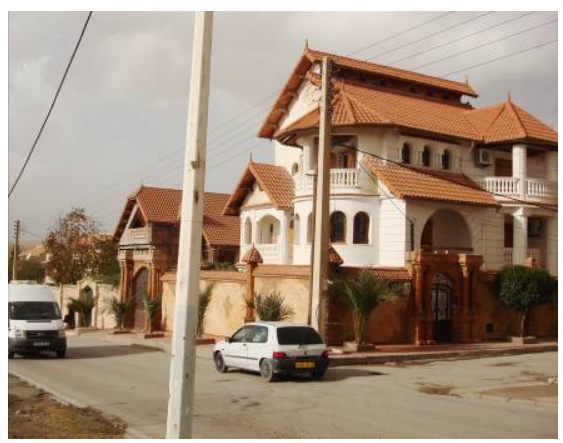

Photo 5: Achieved houses, Subdivision 01; Source: The author (2014)

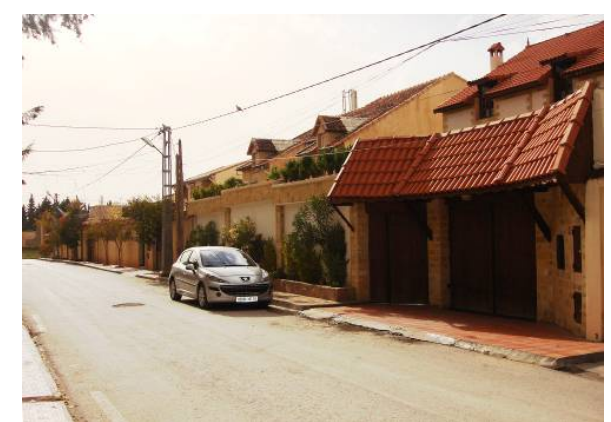

Photo 6: Achieved houses, Subdivision 01; Source: The author (2014)

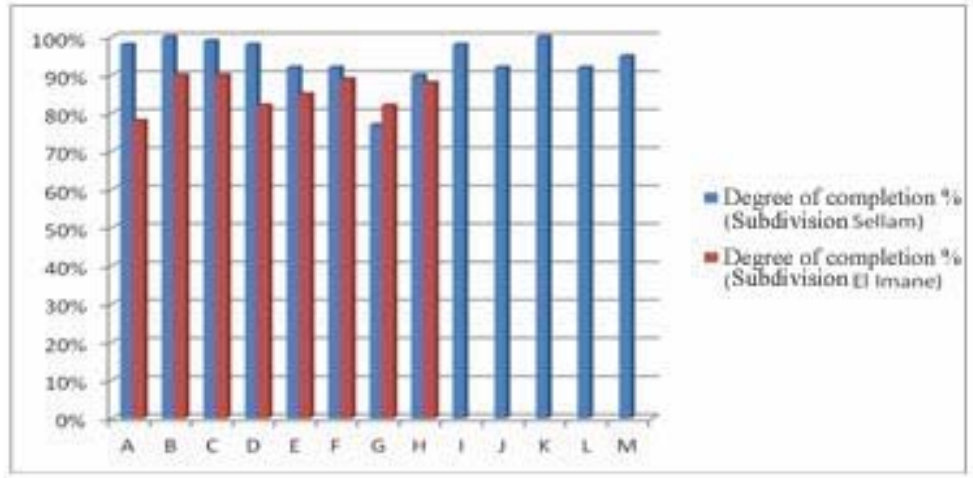

Figure 5: Comparison of the completion degree in islands

Source: Data of the survey established by the author 


\subsection{Fences:}

To constitute a screen of soundproofing, to isolate a residential subdivision from a way with great mechanical traffic and for safety reasons, the inhabitants resort to the heightening of the fences on the boulevard of Scipion (Photo 7: Extra height of fence (baffles and intimacy of the ground floor)

In the residential subdivision, the type of fence is supposed to be defined in the specifications, with a height of 2 to $2.20 \mathrm{~m}$.

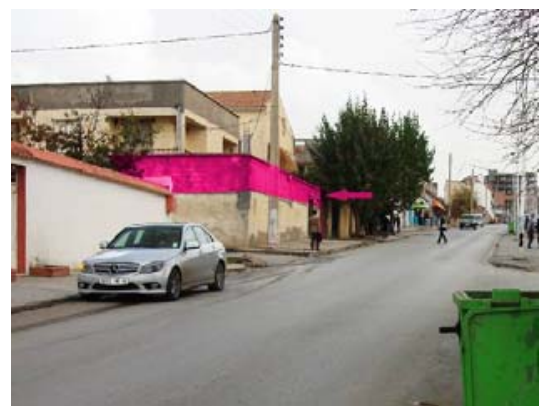

Photo 7: Extra height of fence (Screen); Source: The author (2014)

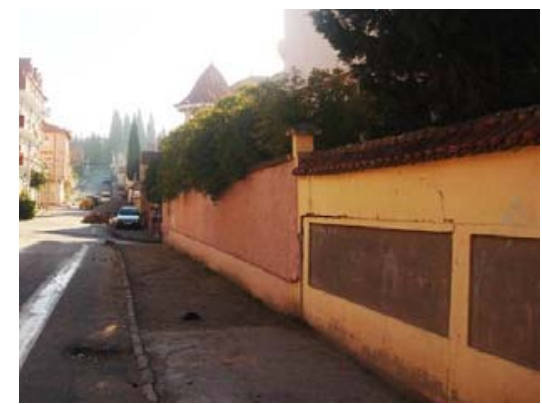

Photo 7 : Fences inside the subdivision 01; Source: The author (2014)

\subsection{Transformations of the external aspect:}

The transformations related to the appearance of the dwellings with the concerted designs (the totality of questioned in the two subdivision live concerted dwellings) point out the big gap between the conceived and the lived dwelling, accentuated because of a lack of confidence between the architect designer as a guide and the inhabitant user and receiver, who should emerge as an actor in a concerted design process.

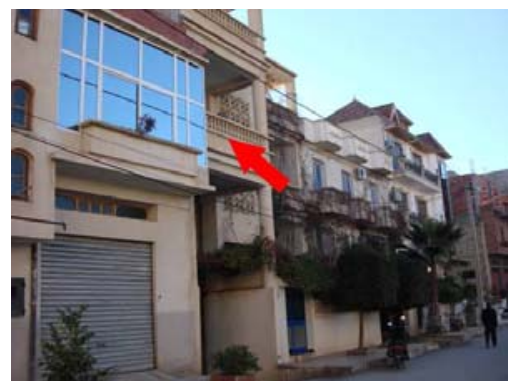

Photo 8: Habitation transformée, lotissement El Imane; Source: The author (2014) 


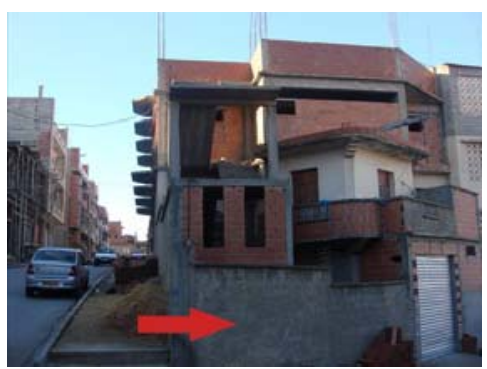

Photo 9: Jardin construit, lotissement El Imane ; Source: The author (2014)

\subsection{Non-residential activities:}

The tradition of creating commercial premises to the ground floor was anchored in the design of the dwelling into the subdivisions, in spite of financial means available to a majority of households, the creation of non residential activities within the subdivision continues.

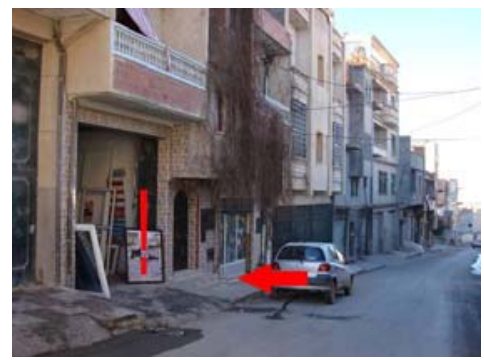

Photo 10: Premise occupied by aluminum joinery, subdivision El Imane; Source: The author (2014)

To restore an order and a harmony, the control institutions could bring solutions to remedy the situation, returning the better life to a more and more demanding population of a quality which for the inhabitants of the subdivision, rhymes with the tranquility and quietude.

\subsection{Presentation of the survey of households:}

"If the fact of respecting the taste of the inhabitant for the interior space of housing is justified, because it is it's field and a place which relates at the bottom only to itself, it is not true any more for external aesthetics qualities of the building, which interests not only all the users of the city, but also the future generations". (DEVILLERS Christian, 1998)

To claim with some replies we sorted samples, for their representativenesses, and the feasibility of the research topic. By the means of the method of the sociological elaborated investigation, to collect reliable data of evaluation of quality within the subdivision, to inventory the transformations even infractions, concerning the appearance and lawful aspects, and finally try to clear up the complex relations between the various factors and shed light on the aspirations to which the decision makers and persons in charge of the built framework, must answer.

The sociological investigation that we carried out, questions the inhabitants of the subdivisions case of study, and verifies several factors

\subsection{Perceived quality:}

The ancient inhabitants of the lot 1 or 2 , have more positive answers relating to the appropriation and perception of the density and quality, with differences recorded according to the age, the sex (on the question of intimacy for example the men claim more intimacy in the two subdivisions and the women are more demanding as regards security in the 1 st subdivision 
with low density, with the inanimate streets..., however the higher educational level in the 1 st subdivision as well as the predominance of a liberal socio professional category that cares about its social status reflection, equipped with the necessary financial resources of their houses and constructions completion and consequently cares about the global image of the subdivision. (Table 1: Summary of some indicators of perceived quality)

Table 1: Summary of some indicators of the received quality

\begin{tabular}{|l|c|c|}
\hline Subdivision/ indicators & Subdivision 1 Sellam & Subdivision 2 El Imane \\
\hline Seniority in the subdivision (years) & 10 & 7 \\
\hline Educational level of the inhabitants & $68 \%$ universitarians & $49 \%$ universitarians \\
\hline Functions & $80 \%$ Liberal & $80 \%$ Public funcion \\
\hline Monthly income & $91 \%<50000$ & $82 \%<50000$ \\
\hline Plurifamiliale dwelling & $6 \%$ & $46 \%$ \\
\hline Fences & $98 \%$ & $6 \%$ \\
\hline Non residential activities & $8 \%$ & $40 \%$ \\
\hline External transformations & $12 \%$ & $18 \%$ \\
\hline Vegetation & $12 \%$ & $6 \%$ \\
\hline Lots number & 111 & 110 \\
\hline (Size) Surface subdivision $\mathbf{( m}^{\mathbf{2}}$ ) & 63810 & 23020,25 \\
\hline Average surface of the lot $\left.\mathbf{( m}^{\mathbf{}}\right)$ & 492,33 & 220,05 \\
\hline Density (lots/hectare) & 22 & 48 \\
\hline Degree of completion $\%$ & $96 \%$ & $68 \%$ \\
\hline Degree of conformity $\%$ & $88 \%$ & $52 \%$ \\
\hline Intimacy $\%$ & $66 \%$ & $78 \%$ \\
\hline Security $\%$ & $72 \%$ & $79 \%$ \\
\hline Perceived quality $\%$ & $92 \%$ & \\
\hline
\end{tabular}

Source: Data of the survey established by the author

The academic level, and the monthly income or financial resources of the households, the density, the mode of occupation of the lots and the dwellings, its surface and configuration and its appearance completed or unfinished, transformed or not transformed, the intimacy and security of the dwelling with the ground floor particularly, as well as the presence of vegetation in and around the dwelling and the outdoor area... are factors influencing the perception of the quality and the density in the subdivision case of study (Figure 40: Quality perceived in the subdivisions and indicators $(\%)$

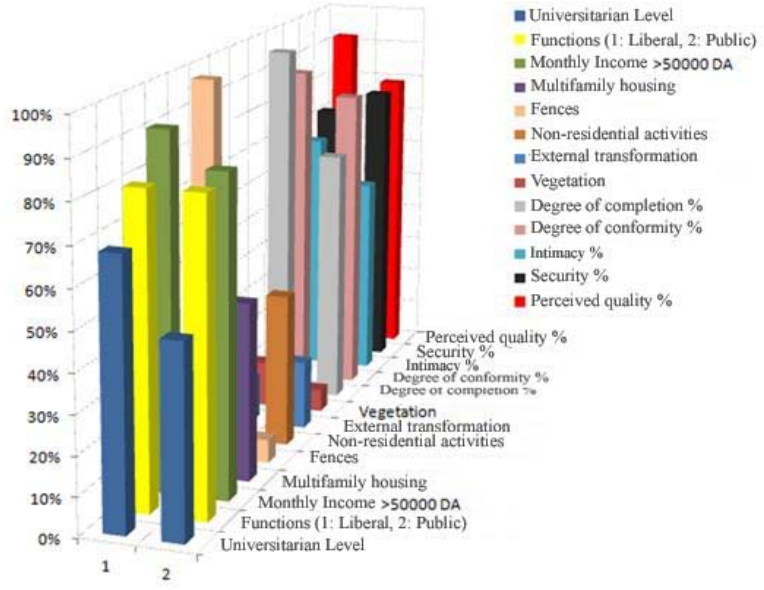

Figure 6: Quality perceived in the lots and the indicators (\%); Source: Data of the survey established by the author 


\section{Conclusion}

The question of the sustainability relative to the exterior aspect of the dwellings in subdivision posed today with acuity in Algeria for example, is a requirement particularly important, where the building should not require short-term major repairs, considering the absence of the tradition of buildings' maintenance.

The degree of completion and the aesthetic sustainability are determining factor for the quality of the building, the choice of the various apparent elements, as well outside as inside, as well as their durability, have a significant impact on the appearance of the building.

The visual and sound landscape perceived by the inhabitant from his dwelling is influenced as much by the prolongations of its dwelling or the quality of the outdoor areas and arrangements, as by the quality of the urban forms which remains determinant of a habitat of quality, so we deduce that the quality of the urban environment is a qualitative criterion for subdivisions.

However the perception of urban quality and residential satisfaction are specific to each context and groups of people, which constitutes a unit experiment that we should not in any case generalize. Just like it is impossible for us to generalize the components of urban quality. Only the identification of the priorities for a given situation would be possible. Since its independence, the urbanization of the Algerian cities was often born from opportunity and not from the mastery, and their vulnerability was accentuated with the abusive consumption of the urban land heritage, rare and non renewable resource.

\section{References}

Boutaba, H., (2001). Le lotissement légale entre la procédure officielle et la procédure parallèle, cas de la ville de Msila, thèse de magister.

Castex, J. \& al, (1977). Formes urbaines de l'îlot à la barre, ED Bordas, Paris

Chaline, C. (2001). "La dynamique urbaine", édition PUF, Paris, 1980."Régénération urbaine". Editions PUF Que sais-je, Paris.

Dehan, P. (1999). "Qualités architecturales et innovation, Ministère De L'Équipement, Des Transports Et Du Logement.

Fouchier, V. (1998). Les densités urbaines et le développement durable ED SGVN, Paris.

Joly, R. (1974). Les racines historiques du lotissement ED Corda Paris.

L'aménagement des lotissements, recommandations " Ministère de l'habitat de l'urbanisme et de la construction OPU 2005, $118 \mathrm{p}$

Bassard, Y. et Villard M. (2002). "les hauts plateaux sétifiens, leurs histoire des temps immémoriaux à 196, Sétif tome1 " Editions Ateliers des presses littéraires, Saint-Estève.

Zuchelli, A. (1984). "Introduction à l'urbanisme opérationnel et à la composition urbaine Vol 3\&4 OPU.

\section{Theses}

Nguyen Lan Phuong, (2006). Densité et Qualité d'habitation au Vietnam, Le cas du quartier Bui Thi Xuan à Hanoi, Mémoire de maitrise en science de l'architecture, Université LAVAL Québec, Canada.

Kehal, K. (2006). Le Lotissement résidentiel : enjeux urbanistiques et développement urbain durable : Cas de Constantine (entre recherche de la qualité urbanistique et la consommation du foncier), mémoire de magistère.

Lacheheb, D.Z. (2012). (Densités et qualités d'habitat individuel, entre dispositif réglementaire et aspect extérieur) mémoire de magistère,

Lecheheb, A. (2007). La problématique des lotissements En tant que fait urbain Entre le dispositif réglementaire et la réalité. Cas de Constantine, mémoire de magistère. 
